\title{
¿|
}

\section{OBJETOS MEDIADOS: PINTURAS MESTIÇAS}

\author{
MEDIATED OBJECTS: MISCEGENATED PAINTINGS
}

\author{
Ricardo de Pellegrin (Unochapecó) \\ ricardoppgart@gmail. com
}

\begin{abstract}
RESUMO
Este artigo apresenta os resultados da pesquisa objetos mediados: pinturas mestiças, desenvolvida entre 2011 e 2013, investigação que se estabeleceu na conjugação da prática artística a uma reflexão teórica, abordando as estratégias poéticas adotadas na concepção e realização desses trabalhos. A proposta instaurou-se nas problemáticas contemporâneas da representação de objetos na pintura (natureza-morta) através do emprego da imagem técnica, processo pictórico relacionado ao conceito de mestiçagem. Identificadas nas estratégias poéticas as questões deslocaram-se dos objetos para o ruído gerado pela mediação técnica (óptica) do modelo.
\end{abstract}

PALAVRAS-CHAVE: Arte Contemporânea. Pintura. Mediação Técnica. Óptica. Ruído.

\section{ABSTRACT}

This paper presents the final results of the research named Mediated objects: miscegenated paintings, which was developed between 2011 and 2013, and it is characterized by presenting an investigation that was established by the combination of artistic practices and theoretical reflections that deal with poetic strategies adopted by the conception and realization of those works. The proposal is based on contemporary issues that cover the representation of objects in painting (still life) through the use of technical image, pictorial process that relates the concept of miscegenation. It was possible to identify in those poetic strategies that the questions moved from the objects to the noise through mediated technique (optic) of the model.

KEYWORDS: Contemporary Art. Painting. Mediation Technique. Optics. Noise.

Este texto configura-se como um apanhado da pesquisa objetos mediados: pinturas mestiças, investigação que foi desenvolvida no Programa de Pós-Graduação em Artes Visuais da Universidade Federal de Santa Maria, na linha de pesquisa Arte e Visualidade, com orientação do professor doutor Paulo César Ribeiro Gomes (UFRGS). É um estudo que se localiza no território das poéticas visuais, no qual foram inquiridas as 


\section{U.}

problemáticas decorrentes do meu processo poético, no período de 2011 e 2013.

- vértice processual/conceitual da poética em questão consiste de uma investigação visual fundada na percepção gerada pela mediação técnica, cujos trabalhos (como resultado final) aglutinam o pictórico à imagem técnica a partir do conceito operatório da mestiçagem. As implicações decorrentes deste processo de mestiçagem resultam da contraposição entre a tecnicidade dos processos de mediação e a materialidade da pintura, construída manualmente por camadas de tinta sobrepostas no suporte.

Nesse sentido, almejou-se realizar trabalhos a partir do confronto entre os diferentes meios de representação bidimensional empregados em diálogo à linguagem pictórica, revitalizando a pintura em consonância com o contexto contemporâneo. Nesse prisma, configura-se como uma abordagem visual para o fenômeno da mediação técnica, enquanto motivadora das mudanças nos paradigmas de representação da pintura.

O artigo foi dividido em dois subtítulos. No primeiro, trato das aproximações entre a pintura e os meios técnicos empregados na mediação do visível. Já no segundo, abordo o pensamento possível para o ruído óptico que é agregado nos trabalhos devido à origem processual técnica.

\section{PINTURA E IMAGENS TÉCNICAS: PROCESSOS MESTIÇOS}

$\mathrm{Na}$ contemporaneidade, as imagens técnicas se tornaram um importante instrumento de mediação entre 0 homem e a realidade. A massificação das tecnologias de produção de imagens provocou uma situação de saturação, geradas e disponibilizadas em fluxo contínuo e desgovernado. Assim, para todo o lugar que olhamos, somos atingidos por informações visuais. Esse confronto vivenciado na atualidade acabou 


\title{
U.
}

definindo novas maneiras de se relacionar com o mundo e, consequentemente, com a arte.

A câmera digital popularizou o processo secular da fotografia graças aos constantes avanços na tecnologia de gravação da imagem. Disponibilizada através de diversos aparatos, toda essa massa de informação visual estabeleceu novos cânones perceptivos, conformando o olhar do sujeito aos modos de ver da máquina; indivíduo que, para além de qualquer ingenuidade, dialoga com essa realidade estabelecida. Sobre a influência das imagens técnicas na formação do olhar do sujeito contemporâneo, o crítico Tadeu Chiarelli afirma que:

\begin{abstract}
Essa nova geração, nascida após o termino da Segunda Guerra Mundial, vivenciou de maneira mais totalizadora (praticamente do berço), os novos meios de comunicação sobretudo a televisão, mas também revistas, cinema etc. -, recebendo sem nenhum tipo de resistência preconcebida um universo de informações fragmentado, cheio de imagens das mais diversas épocas e procedências, todas elas homogeneizadas em suas diferenças por essas mesmas mídias. (CHIARELLI, 2001, p. 265).
\end{abstract}

As implicações da presença das imagens técnicas se refletem na aparência das obras de arte, mas de modo especial na pintura. Ciente desta contaminação, Klaus Honnef tece uma leitura da pintura que revela a influência das imagens técnicas no modo de ver e de criar dos artistas atuais. Consoante o autor:

\begin{abstract}
Através do desenvolvimento específico da pintura contemporânea, pode-se verificar facilmente como a imagem fotográfica do mundo influencia tão acentuadamente 0 modo de ver e de pensar. De um lado, imagens que recusam qualquer espécie de modelo, que nada representam, e que devem ser percebidas e compreendidas simplesmente como imagens autônomas; no outro lado, imagens inspiradas na fotografia sem, no entanto, constituírem reproduções fotográficas ou duplicados. (HONNEF, 1990, p. 73).
\end{abstract}

A pintura, a fotografia e o cinema podem ser considerados os principais meios responsáveis pelas mudanças na concepção da imagem no ocidente, com consequências intimamente ligadas à 


\section{《)}

formação do olhar do espectador nos diferentes períodos. As aproximações entre a pintura e os meios técnicos de produção sempre ocorreram, entretanto, é na contemporaneidade que pode ser verificada grande efervescência desse tipo de conduta poética mestiça.

A produção pictórica, na maioria dos casos, perpassa a constituição de um estudo preparatório, esboço onde constam as diretrizes para a execução do trabalho. O método de trabalho mais tradicional pressupõe a observação direta do modelo e sua replicação no suporte, no qual o artista tateia a forma em busca do lugar preciso de cada traço.

Segundo David Hockney, fazer a olho refere-se:

[...] ao modo como o artista se senta na frente de um modelo e desenha ou pinta um retrato usando apenas a mão e olho e nada mais, observando a figura e tentando depois recriar a semelhança no papel ou na tela. (HOCKNEY, 2001, p. 23).

Entretanto, os meios técnicos de produção de imagens fazem a passagem mecânica do mundo visível para o bidimensional. Essas imagens se constituem a partir de uma organização particular, aparência que diverge da visualidade produzida através do fazer a olho.

Parece-me que perante a profusão de imagens à qual o sujeito contemporâneo é submetido, desaprendemos a olhar sem a mediação da imagem técnica, tornando-se natural que essa imagem, em especial a fotografia, seja um recurso amplamente utilizado pelos pintores no processo de trabalho. Essa mediação técnica não disponibiliza a mesma experiência de observação do modelo, pois traduz um correspondente plano de maneira específica e ruidosa.

A diferença fundamental entre os procedimentos mencionados está no tipo de experiência visual que é utilizada na concepção da imagem: a primeira dá conta da visão binocular, que corresponde à percepção humana; a outra, da visão da 


\title{
\|
}

máquina, monocular, mediada por procedimentos técnicos. No processo dos pintores que trabalham a partir da fotografia, a imagem técnica ocupa o lugar do bloco de desenhos para os artistas que partem do fazer a olho, conforme afirma Karl Ruhrberg:

\begin{abstract}
A fotografia - ou série de fotografias - é um instrumento tão importante quanto é o bloco de esboços para outros pintores. Consequentemente, a sua obra criativa começa logo na escolha do motivo, na seleção de fotografias que em geral eles mesmos tiraram, por vezes com uma máquina fotográfica manipulada. (RUHRBERG, 2005, p. 335).
\end{abstract}

A escolha pela imagem fotográfica como recurso para constituição dos estudos decorre do fato de que este meio não se limita à finalidade de reproduzir o modelo, mas produz uma aparência específica. No meu processo, os objetos são dispostos em um modelo e o espaço que eles ocupam recebe uma iluminação específica. A câmera passeia entre as personagens, aproximando-se destas e disponibilizando um ângulo de observação diferenciado da experiência cotidiana com estes modelos. As fotografias resultam do flanar da câmera fotográfica entre os objetos.

A partir da ampliação destas imagens técnicas, reproduzidas manualmente sobre a tela através da projeção, há o estabelecimento de uma tensão entre os meios empregados, com a tecnicidade da imagem técnica e a materialidade pictórica. As práticas de cruzamento instituídas nessa investigação seguem a definição de conduta mestiça definida por Icleia Borsa Cattani (2007). A autora define que:

\footnotetext{
Os cruzamentos que suscitam relações com o conceito de mestiçagem são os que acolhem sentidos múltiplos, permanecendo em tensão na obra a partir de um princípio de agregação que não visa fundi-los numa totalidade única, mas mantê-los em constante pulsação. (CATTANI 2007, p. 11).
}

A transposição da fotografia para a pintura, em óleo sobre tela, faz parte da gama de procedimentos escolhidos para negar 


\section{《)}

a banalidade e conferir outro status para a imagem. A superficialidade da fotografia é transmutada para o pictórico, deslocando-a da saturação cotidiana, estabelecendo um confronto com a aparência e as possibilidades de reprodução providos das imagens técnicas.

Inegavelmente, a tendência de produzir pinturas na contemporaneidade caracteriza-se como uma postura contraditória diante da arte digital, movimento cuja principal consequência foi a desmaterialização do objeto artístico. Na minha prática, tal conflito se evidencia na materialidade da pintura a óleo, meio visual que se mantém singularizado pela condição específica de observação e sua impossibilidade - até certo ponto - de reprodução técnica.

$\mathrm{Na}$ tela, o processo pictórico inicia com a imagem fotográfica projetada sobre o suporte. Conforme as diretrizes determinadas pela projeção, sem o uso de um desenho preliminar, a tinta é aplicada em suaves veladuras muito adelgaçadas com solvente. A opção pelo emprego de camadas menos encorpadas de pigmento pretende um aspecto opaco na pintura, sem o brilho característico da tinta a óleo. Produzindo manchas de cor sobre a tela são decalcados os contrastes mais acentuados de luz e sombra, áreas que estruturam a imagem.

A aplicação das cores segue uma lógica pré-determinada: iniciando com tonalidades de amarelo claro, passando para os laranjas, depois os vermelhos, os verdes e os violetas, os azuis (Figura 01). A gradação é resultado da diluição da tinta em solvente, ou seja, o pigmento branco não é utilizado para obter tonalidades mais claras, do mesmo modo que o preto não é empregado para escurecer as matizes.
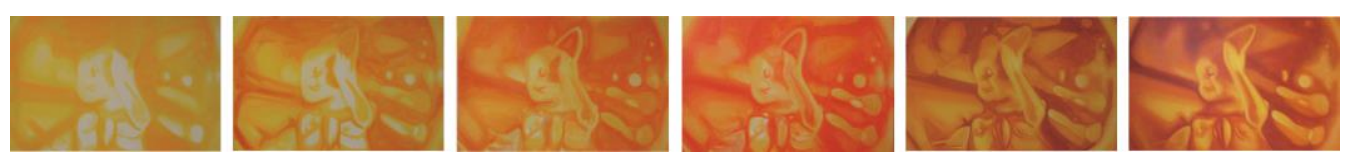

ISSN: 2447-1267 Santa Catarina, v.2, n.2, ano 2, fevereiro de 2016. 


\section{U.}

Figura 01 - Processo de construção da pintura Nu artístico - Zoom, 2011. Fonte: acervo pessoal do autor.

A estratégia de pintar por camadas de cor que cobrem, com menor ou maior intensidade, toda a superfície da tela é uma prática compartilhada por diversos artistas na contemporaneidade. A minha opção por esse procedimento deve-se ao objetivo de conferir uma unidade cromática ao trabalho, aproximando-se da lógica de construção da cor que ocorre no processo fotográfico (por camadas de cor que se sobrepõem).

A respeito do procedimento de construção da cor na pintura através de camadas, Jacques Aumont afirma que:

[...] pode-se sempre imaginar um pintor que se aplica em pintar, sucessivamente, três camadas monocromáticas, em cores primárias, sobre toda a superfície: é complicado, mas teoricamente possível. (AUMONT, 2004, p. 186).

Apesar de compartilhar do mesmo procedimento pictórico mencionado por Aumont, aplicação da tinta em camadas a partir de projeção, as pinturas que integram minha investigação poética resultam de processos menos arbitrários.

As qualidades da pintura são exaltadas em alguns dos trabalhos que realizei, como pode ser observado em Estação Destempo (2012) (Figura 02), proposta de site-specific produzida durante o evento arte\#ocupasm (2012). Realizada com um número restrito de cores, alguns tons de amarelo, laranjas, vermelhos e violetas, aplicadas de modo a evidenciar as qualidades do material, com escorridos, manchas, assumindo os desvios da pintura na imagem. Tal trabalho foi efetuado em uma zona da pintura onde o artista perde o controle do material. 


\section{REVISTA}

\section{APOTHEKE}



Figura 02 - Estação Destempo, 2012, acrílica sobre parede, 300 x $600 \mathrm{~cm}$. Fonte: acervo pessoal do autor.

\section{RUÍDOS ÓPTICOS}

O processo de mediação do visível pela técnica pode ser pensado, caso seja considerado como um circuito de comunicação, como um meio cuja passagem subverte a informação, agregando ruído à mensagem. Pois, por exemplo, por maior que seja a capacidade da fotografia de gerar uma mimese do visível, tal imagem técnica sempre será uma interpretação ruidosa do real.

Nesta investigação, o conceito de ruído baseia-se no pensamento do filósofo Michel Serres (1982). Serres considera - ruído como parte indissociável da comunicação, por outro lado, afirma que é o não comunicado, pertencente à esfera do caos. Na obra literária The Parasite (1982), Serres concebe a figura do parasita como o ruído em um canal de comunicação. A mensagem, nos termos de Serres, não pode ser concebida sem desvios, uma vez que:

[...] não conhecemos sistema que funcione perfeitamente, ou seja, sem perdas, fugas, desgastes, erros, acidentes, opacidades - um sistema cujo retorno é de um por um. (SERRES apud LECHTE, 2002, p. 101) 


\section{A $\mid$ REVISTA}

É com essas intenções que aplico os instrumentos de mediação da imagem em meu processo poético, a fim de produzir, no ruído agregado, uma informação diferenciada, que apenas seja possível através do caráter mediado disponibilizado pela imagem técnica. Os ruídos gerados através do uso de aparatos ópticos, na seção fotográfica, ampliam as possibilidades interpretativas, pois a imagem se torna mais subjetiva, como pode ser observado na tela Trio de soldadinhos mutilados (2011) (Figura 03)

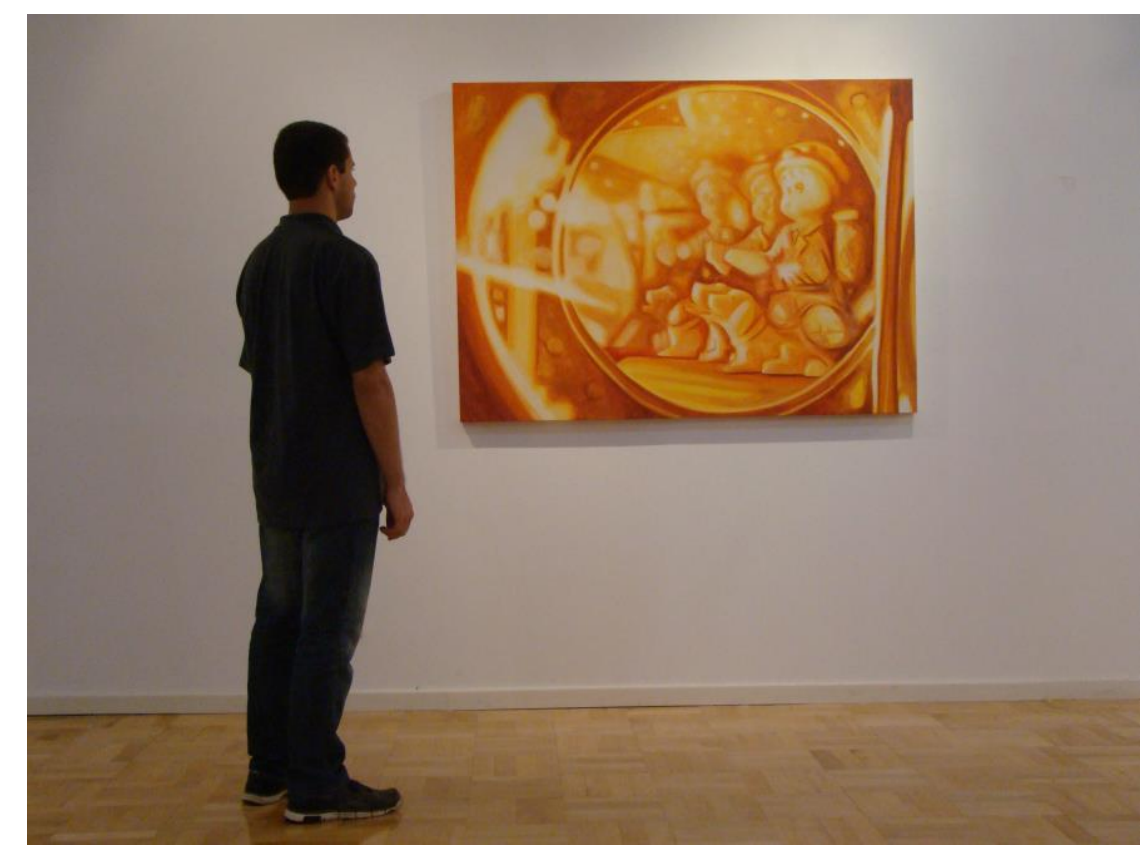

Figura 03 - Trio de soldadinhos mutilados, 2011, óleo sobre tela, 110 x 150 cm. Fonte: acervo pessoal do autor.

No momento em que elaboro os estudos fotográficos, não domino os efeitos que serão produzidos devido à informalidade dos recursos que são empregados. Pois, apesar das escolhas dos objetos e da luz ser elementar, é o acúmulo dos ruídos visuais da óptica que determina a aparência final desses estudos. Corrompendo o reconhecimento das figuras, essas imagens transmitem menos, no sentido de uma mensagem direta, exigindo mais do espectador. A opacidade presente nestas imagens 


\section{A.}

instiga a busca por maneiras de penetrar na trama de sentidos evocados.

- trabalho Abstração Óptica (2012) é resultado de uma série de três imagens (Figura 04) nas quais identifico que, devido ao acúmulo do ruído óptico, o modelo foi deturpado ao extremo, impossibilitando seu reconhecimento, mas ele permanece lá, enquanto vestígio da sua presença. A deformação, neste caso, decorre do uso de um globo de vidro cheio de água que adquire a função de lente durante a produção das fotografias/estudos.
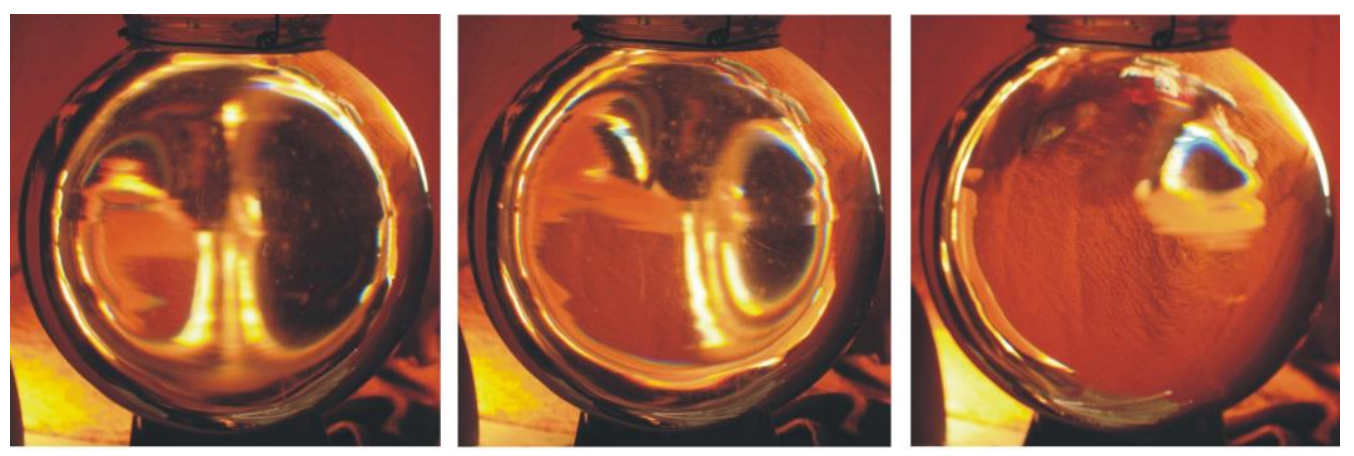

Figura 04 - Abstração óptica [estudos], 2011, fotografias usando globo de vidro como lente. Fonte: acervo pessoal do autor.

A óptica é fundamental nesta investigação poética, visto que a motivação se encontra nos recursos empregados como ferramenta para mediar o mundo visível, tornando-o bidimensional, ou seja, meios que direcionam o olhar em sentidos bifurcados. A opacidade, que vem a ser gerada pelo emprego de recursos ópticos no processo de captura da imagem, tem a função de velar o referente em prol de uma abordagem menos taxativa da figuração. A abertura de sentidos, decorrente das distorções ópticas, agrega ao referente um ruído processual, emprego que alarga as possíveis interpretações da imagem. Como reflexo da capacidade de mimese intrínseca à imagem fotográfica, percebemos que mesmo a representação mais precisa acaba sendo dotada de minúcias interpretativas que estão além da superfície.

ISSN: 2447-1267 Santa Catarina, v.2, n.2, ano 2, fevereiro de 2016. 


\section{U.}

As motivações poéticas que localizo na tecnologia podem ser relacionadas ao conceito de low tech, termo que se define na oposição à expressão high tech, o qual constitui-se de uma tendência dedicada à investigação de tecnologias do passado. Fundamental salientar que o conceito de tecnologia está subordinado ao período histórico, pois, decorrente dos constantes avanços e inovações, um procedimento considerado inovador em uma época se torna retrógrado pouco tempo depois, e este ritmo de descarte está cada vez mais acelerado.

$\mathrm{Na}$ produção das pinturas que realizo, os recursos ópticos simplificados, tais como lupas e globos de água, são empregados como lentes na elaboração dos estudos fotográficos, imagens decorrentes de circunstâncias específicas de mediação óptica que são transpostas para a linguagem pictórica. Tais aparatos ópticos, anexados informalmente à câmera, subvertem o controle dos comandos do mecanismo fotográfico, proporcionando uma experiência de produção mais subjetiva, ou seja, menos determinada pelas regras da câmera.

Neste sentido é possível estabelecer uma aproximação com as considerações de Vilém Flusser (2008) a respeito do funcionário, termo que o autor emprega para o individuo que se vale dos aparatos técnicos sem transcender o dispositivo, no intuito de elucidar minhas pretensões de transpor o funcionamento da câmera. Segundo Flusser:

O seu desafio é o de fazer imagens que sejam pouco prováveis do ponto de vista do programa do aparelho. o seu desafio é o de agir contra o programa dos aparelhos no interior do próprio programa. (FLUSSER, 2008, p. 28).

Sobre as anamorfoses que produzo com baixa tecnologia, o primordial não se encontra na impossibilidade de fazer imagens similares por meio de recursos da alta tecnologia, pois, até certo ponto, os efeitos obtidos podem ser atingidos com lentes especiais ou simulados em programas de edição de imagens; mas 


\section{《)}

- que os diferencia é a subversão dos sistemas prédeterminados da câmera - uma tentativa de desestabilizar a linearidade técnica da captação da imagem fotográfica, investindo na aproximação do homem com a máquina.

A escala mais facilmente manipulável dos mecanismos simplificados, no meu caso os aparatos ópticos, permite uma articulação poética mais experimental. Esse emprego, tateando possibilidades, é menos arbitrário se comparado ao uso de recursos high tech, cujo resultado final é desde o principio determinado pelo aparato. Nesse sentido, compartilho de motivações similares às que João Carlos Machado (2009) revela a respeito de seu processo de trabalho:

\footnotetext{
Entre as vantagens do Low Tech sobre o High Tech, do meu ponto de vista poético, está a escala mais facilmente manipulável de seus materiais e componentes e a possibilidade de deixar à mostra os mecanismos que produzem os efeitos sonoros e visuais emitidos pelos aparelhos. Ele tem o potencial de deixar visível o que é não visível no digital. (MACHADO, 2009, p. 612-613).
}

$\mathrm{Na}$ trajetória desta pesquisa, o interesse pela low tech evidenciou-se nos trabalhos realizados. Neste sentido, os aparatos ópticos, empregados como lentes no processo fotográfico - estudos transpostos para pintura - serviram de motivação para outros trabalhos, propostas que extrapolam as convenções da pintura. Estas tecnologias foram aplicadas no desenvolvimento de aparatos que geram imagens com qualidades e princípios ópticos.

No processo de desenvolvimento do projetor que integra o trabalho Pintura (2012) (Figura 05), utilizei lentes similares às que costumeiramente emprego frente à câmera. A proposta consiste de um projetor caseiro construido com sobras de madeira, lentes de lupa, transparência com impressão color laser, uma lâmpada alógena de jardim e materiais de instalação elétrica, cuja imagem gerada é decalcada sobre uma tela, permanecendo sobrepostas pintura e projeção. o estágio 


\section{A.}

conferido à essa pintura é similar ao primeiro momento do processo pictórico que realizo, quando o desenho é transferido para a tela apenas em pigmento amarelo.

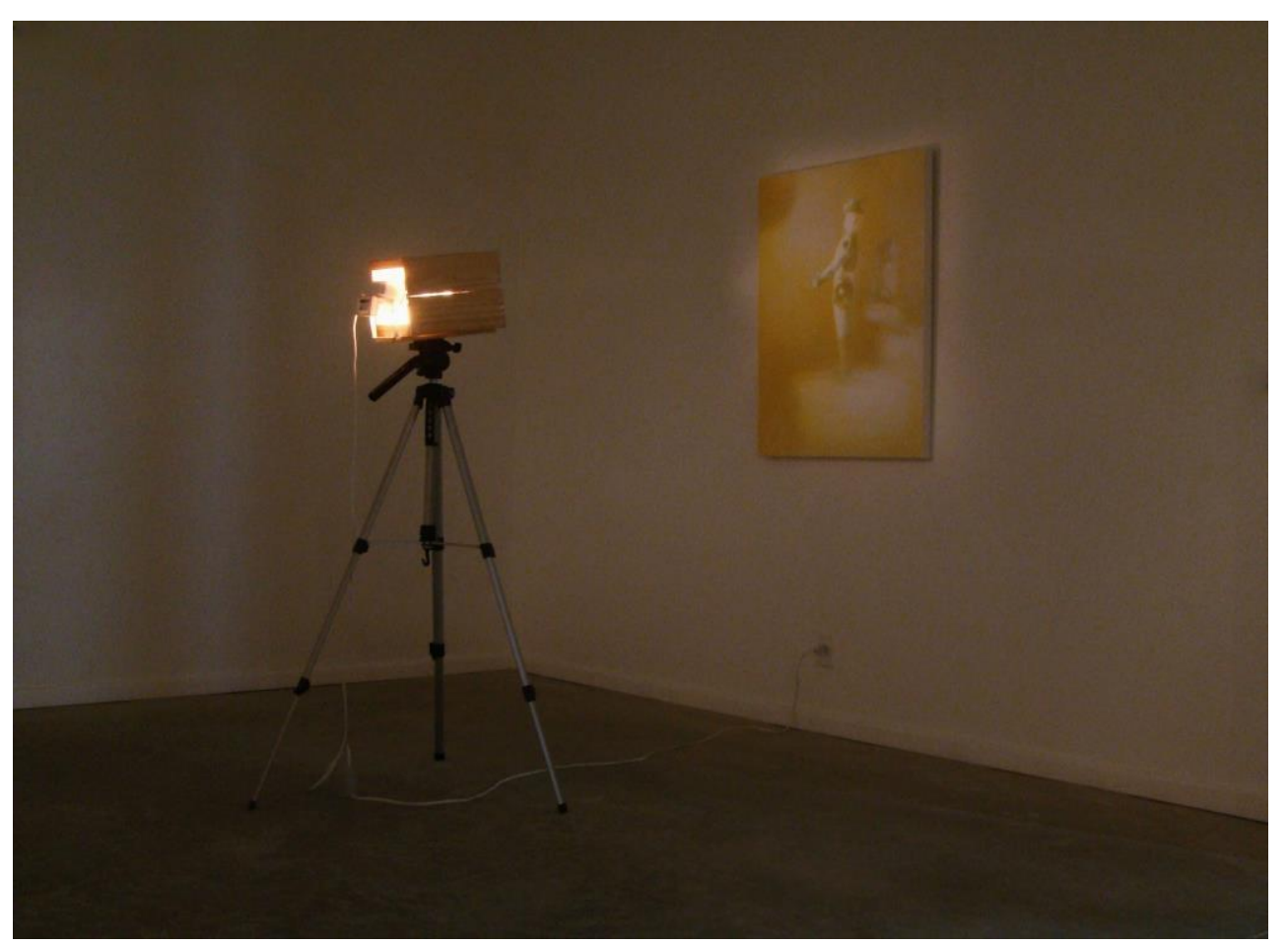

Figura 05 - Pintura, 2012, óleo sobre tela e projetor artesanal, lentes de

lupa, transparência com impressão color laser, madeira, lâmpada alógena, instalação elétrica, tripé. Fonte: acervo pessoal do autor.

Neste sentido, pensando nos aparatos low tech empregados na minha poética, percebo que o uso da óptica pode ser compreendido como uma investida para repensar a presença e o impacto da tecnologia na percepção do sujeito contemporâneo, indivíduo que, como comentado anteriormente, habituou-se a experienciar a realidade através da mediação técnica. Estes instrumentos rudimentares, por outro lado, contrariam a presença massiva da tecnologia de ponta nos processos artísticos atuais, apontando para possibilidades de investigação que se opõe a invisibilidade dos processos digitais e ao maquinocentrismo (MACHADO, 2009).

\section{Considerações finais}




\section{ע|}

O desenvolvimento do presente estudo buscou problematizar as estratégias poéticas adotadas na produção visual, partindo do ponto de vista artista instaurador, no qual foram evidenciadas as implicações morfológicas, sintáticas e semânticas dos procedimentos empregados na concepção e concretização dos trabalhos. Entretanto, para além do objetivo de se chegar a um resultado, a pesquisa e a dissertação se impuseram, principalmente, como um processo de continuidade e de aprofundamento do discurso poético pessoal.

Neste sentido, torna-se pertinente ressaltar o notório amadurecimento das questões investigadas, cujo foco migrou das problemáticas relacionadas ao gênero natureza-morta para o ruído óptico decorrente da mediação técnica no processo de representação. Desse modo, o resultado final dos trabalhos passou a evidenciar, para além da pintura, outros aspectos relevantes em minha poética, como as possibilidades de instituir projeções de imagens por meio de aparatos ópticos simplificados. Assim, o conjunto de trabalhos reunido nessa pesquisa demonstra, além do resultado do processo na instauração das obras, propostas que apontaram para caminhos distintos que partiram da mesma gênese conceitual.

As investigações no campo da low tech revelaram que a óptica pode ser compreendida como um elemento primordial dos processos de mediação técnica, sendo responsável por grande parte das interferências verificadas na aparência das imagens de origem tecnológica. Esta genealogia torna-se possível devido os vestígios visuais que decorrem do emprego da tecnologia na prática artística, experiências que remontam à tradição da arte holandesa do século XVI, onde Jan Vermeer, condicionado à percepção gerada pela mediação do visível através de lentes, empreende uma abordagem diferenciada para a representação bidimensional. 


\section{Rerysta \\ A APOTHEKE}

Entretanto, na contemporaneidade, a massiva presença das imagens técnicas no cotidiano transformou esses códigos visuais ópticos em soluções usuais, como as variações de foco entre os planos da imagem. Neste contexto, se por um lado as inovações técnicas facilitaram a captura e reprodução do visível, por outro, sua agilidade e massificação produziram um esvaziamento de sentido para o meio, fazendo com que sejam consideradas imagens descartáveis. Deste modo, nas artes, a pintura tem se mostrado como uma alternativa capaz de interromper este fluxo de descarte, como ocorre no conjunto de telas que foi apresentado ao longo desse trabalho.

Os embates que surgem por esta presença das imagens técnicas repercutem na prática artística de modo abrangente, através das experiências de percepção disponibilizadas ao sujeito contemporâneo por meio da aparência ruidosa da imagem técnica, tal referência é traduzida para a linguagem pictórica. Neste sentido, ao tratar da natureza-morta, agrego aos saberes da tradição ocidental sobre este gênero às especificidades estéticas da mediação técnica, situação que considero ser um traço da contemporaneidade. Entretanto, a materialidade da pintura, devido às qualidades plásticas opostas às da imagem técnica, confere outro status para essas imagens, retirando-as da banalidade a qual sua origem processual condena.

Contrapondo-se ao uso inicial da mediação técnica em meu processo, que serviu como estudo para o trabalho pictórico, os trabalhos que foram realizados por meio do emprego direto de mecanismos low tech, demonstram outras perspectivas de confronto com a mestiçagem. São propostas que escapam da concepção tradicional da pintura, porém valem-se dela para fundamentar o seu discurso visual.

Deste modo, a poética em questão não abrangeu apenas as pinturas produzidas manualmente em óleo sobre tela, mas ao 


\section{Rerysta \\ APOTHEKE}

investigar desdobramentos específicos, a partir do processo instaurado, denunciou diversas possibilidades de mestiçagens entre a pintura e a mediação técnica. Estas aproximações entre pintura e low tech, assunto que desperta grande interesse pessoal, correspondem a um campo fértil para a continuidade da pesquisa poética, inserindo-se nas discussões contemporâneas a respeito da co-presença de meios pelo viés da mestiçagem.

\section{REFERÊNCIAS BIBLIOGRÁFICAS}

AUMONT, Jacques. O olho interminável: cinema e pintura. Tradução: Eloísa Araújo Ribeiro. São Paulo: Cosac \& Naify, 2004 .

CATTANI, Icleia Borsa. Poiéticas e Poéticas da Mestiçagem. In: Mestiçagens na arte contemporânea. Porto Alegre: Editora da UFRGS, 2007. pp. 11-17.

CHIARELLI, Tadeu. Considerações sobre o uso de imagens de segunda geração na arte contemporânea. In: BASBAUM, Ricardo [org.]. Arte Contemporânea Brasileira. Rio de Janeiro: Marcad'Agua, 2001. pp. 257-270.

FLUSSER, Vilém. O universo das imagens técnicas: Elogio da superficialidade. São Paulo: Annablume, 2008.

HOCKNEY, David. o conhecimento secreto: Redescobrindo as técnicas perdidas dos grandes mestres. São Paulo: Cosac \& Naify, 2001.

HONNEF, Klaus. Imagens num mundo de imagens. In: Arte

Contemporânea. Colónia: Taschen, 1990. pp. 73-85.

LECHTE, John. Cinquenta pensadores contemporâneos essenciais: do estruturalismo à pós-modernidade. Rio de Janeiro: DIFEL, 2002 .

MACHADO, João Carlos. O Low Tech frente ao maquinocentrismo e a invisibilidade dos processos digitais. In: Anais do $18^{\circ}$ Encontro Nacional da ANPAP, Salvador: EDUFBA, 2009. pp. 609622 .

RUHRBERG, Karl. Arte do Século xx: Pintura. Tradução: Ida Boavida. Colónia: Taschen, 2005. 


\section{R| Revrsta \\ A APOTHEKE}

Ricardo de Pellegrin (nome artístico Ricardo Garlet). Artista Visual, Mestre em Artes Visuais pelo Programa de Pós-Graduação em Artes Visuais da UFSM, Bacharel em Artes Visuais com Habilitação em Pintura e Licenciatura pela UFPEL. Docente no curso de Artes Visuais da Unochapecó. 